\title{
PREOPERATIVE ENDOCRINOLOGICAL EVALUATION OF PATIENTS APPLY FOR BARIATRIC SURGERY
}

\author{
ILKAY CAKIR ${ }^{1}$, YASIN SIMSEK ${ }^{2}$, RIZA KUTANIS ${ }^{3}$,SERKAN MENEKSE ${ }^{4}$,EMINE ISIL USTUN ${ }^{5}$, DEDE SIT6 \\ 1-BAGCILAR RESEARCH AND EDUCATION HOSPITAL, DEPARTMENT OF ENDOCRINOLOGY \\ 2-HITIT UNIVERSITY HOSPITAL, DEPARTMENT OF ENDOCRINOLOGY \\ 3-BAGCILAR RESEARCH AND EDUCATION HOSPITAL, DEPARTMENT OF GENERAL SURGERY \\ 4-BAGCILAR RESEARCH AND EDUCATION HOSPITAL, DEPARTMENT OF ONCOLOGY \\ 5-BAGCILAR RESEARCH AND EDUCATION HOSPITAL, DEPARTMENT OF PHYSICAL THERAPY \\ 6-BAGCILAR RESEARCH AND EDUCATION HOSPITAL, DEPARTMENT OF INTERNAL MEDICINE
}

Since bariatric surgery is considered to be a more effective treatment modality for morbid obesity, a growing number of patients have been referred to endocrinology clinics in order to exclude an underlying cause. Routine preoperative testing to screen Cushing's Syndrome (CS) or hypothyroidism is still debatable. The aim of this study is to evaluate the accuracy of routine testing in preoperative endocrinological evaluation .

Clinical files of 164 patients who applied for bariatric surgery to our outpatient clinic between January 2014 and January 2015 were reviewed. Cortisol levels following lowdose dexamethasone administration, and free thyroxine, thyrotropin (TSH) were measured to exclude CS and hypothyroidism respectively. Serum cortisol $<1.8 \mu \mathrm{g} / \mathrm{dl}$ was the cut-off point for normal suppression. We also have measured $\mathrm{HbA} 1 \mathrm{C}$, insülin, and fasting glucose as a part of our pre-surgical protocol.HOMA-IR was used to determine insulin resistance.

\section{Results:}

Hundredsixtyfour patients (43 men and 121 women) with a mean age of $39,96 \pm 10,95$ years and a mean BMI of 49,50 $\pm 34,36 \mathrm{~kg} / \mathrm{m}^{2}$ were reviewed. Only in 1 patient pseudo cushing syndrome was considered. Primary subclinical hypothyroidism was $12 \%$, and primary subclinical hyperthyroidism was $1 \%$, while 151 patients were euthyroidic (92\%)

The prevalence of known Diabetes Mellitus was $26 \%$. No new patient of Diabetes Mellitus was diagnosed, while the prevalence of Impaired Fasting Glucose was $38 \%$. Mean HOMA-IR levels were 5,94 $\pm 3,5$ and mean $\mathrm{HbA} 1 \mathrm{C}$ levels were $5,6 \pm 0,4 \%$ when previously known diabetics were excluded.

Routine screening for CS, hypothyroidism seems to be not required and may cause needless expenditures for national health systems in patients who apply for preoperative evaluation for bariatric surgery. For the time being, diagnostic tests for CS and hypothyroidism in morbidly obese patients should be limited to patients who have accompanying more clinical signs and symptoms.

1- Guaraldi F, Salvatori R. Cushing syndrome: maybe not so uncommon of an endocrine disease. J Am Board Fam Med. 2012 MarApr;25(2):199-208.

2- Fierabracci P, Pinchera A, Martinelli S, Scartabelli G, Salvetti G, Giannetti M, Pucci A, Galli G, Ricco I, Querci G, Rago T, Di Salvo C, Anselmino M, Vitti P, Santini F. Prevalence of endocrine diseases in morbidly obese patients scheduled for bariatric surgery: beyond diabetes. Obes Surg. 2011 Jan;21(1):54-60 